\title{
Smoking cessation counseling: Attitude in the background of poor practice compliance among Palestinian primary health care physicians: a cross-sectional study
}

\author{
Beesan Maraqa $^{* 1,3}$, Zaher Nazzal ${ }^{2}$, Jurouh Jabareen ${ }^{1,3}$, Kamal Al-Shakhrah $^{1}$ \\ ${ }^{1}$ Primary Health Directorate, Palestinian Ministry of Health, Palestine \\ ${ }^{2}$ Department of Family and Community Medicine, Faculty of Medicine and Health Sciences, An-Najah National University, \\ Nablus, Palestine \\ ${ }^{3}$ Faculty of Medicine and Health Sciences, An-Najah National University Nablus, Palestine
}

Received: July 6, 2020

DOI: $10.5430 /$ ijh.v7n1p37
Accepted: November 10, 2020 Online Published: November 27, 2020

URL: https://doi.org/10.5430/ijh.v7n1p37

\begin{abstract}
Objectives: Healthcare systems have primary responsibility for treating tobacco dependence. Despite its proven effectiveness, international studies have shown that smoking cessation advice to patients in primary health care is suboptimal. This study aimed at assessing Palestinian PHC physicians' compliance and attitude towards smoking cessation counseling and their determinants. Methods: The study utilized a cross-sectional study design using a self-reported questionnaire targeted general practitioners, family medicine doctors, obstetrics \& gynecologists, and dentists working at PHC Centers in Palestine from April to September 2019. A proportional stratified random sampling method was used. Socio-demographic, medical experience, if received any training in smoking cessation counseling, smoking history, practice compliance, knowledge, confidence, and attitude, were assessed.

Results: Two-hundred ninety-four PHC physicians participated in the study with a high response rate. More than half (53\%) were between 31-45 years of age. Most of them (76.5\%) were general practitioners seeing more than 30 patients per day (66\%), and only $15 \%(\mathrm{n}=40)$ get training about smoking cessation counseling. Practice compliance was low; only $39(13.3 \%)$ reported adherence to smoking cessation practice. The participant physicians' attitude level was good as the overall attitude score mean $75.1 \pm 9.6$. A positive attitude, assigned as any score $\geq 65$, was observed in $87.7 \%(\mathrm{n}=258)$ of physicians. Job title, experience, and knowledge are predictors of a positive attitude towards smoking cessation counseling.

Conclusions: Building a supportive environment, improving physicians' capabilities will reflect on their self-efficacy and their confidence level and enhance their practice in smoking cessation counseling.
\end{abstract}

Key Words: Smoking cessation counseling, Attitude, Primary health care, Physicians, Palestine

\footnotetext{
${ }^{*}$ Correspondence: Beesan Maraqa; Email: dr.beesan.maraqa@ gmail.com; Address: Primary Health Directorate, Palestinian Ministry of Health, Palestine.
} 


\section{INTRODUCTION}

More than a billion smokers worldwide who are addicted to cigarettes are victims of the tobacco epidemic. Many tobacco consumers can quit, but few obtain assistance and encouragement to overcome their dependency. Health care services have primary responsibility for the treatment of tobacco dependency. ${ }^{[1]}$

Health care organizations also emphasized the value of a holistic approach to eliminating tobacco use's health and economic burden. ${ }^{[2,3]}$ As a result, evidence-based tobacco prevention initiatives have been introduced and shown to reduce smoking rates as well as tobacco-related diseases and deaths. ${ }^{[4]}$ Programs should include tobacco cessation advice incorporated into primary health care (PHC) services, free accessible telephone helplines (known as quitlines), and access to low-cost medicines. ${ }^{[1]}$

Despite its proven effectiveness, international studies have shown that smoking cessation advice to patients is suboptimal. ${ }^{[5,6]}$ A significant body of literature has attempted to investigate factors that affect the counseling cessation practice. It has shown that physicians' attitude towards this practice is one of the significant contributors. ${ }^{[7,8]}$ On the other hand, the positive attitude towards the cessation of counseling among Pakistan practitioners was not adequate for practice compliance. They did not feel fully assured about their intervention's effectiveness and lack essential expertise and skills in counseling practice. ${ }^{[9]}$ Also, a survey of Italian PHC physicians reported a positive attitude towards the provision of smoking cessation interventions and the need to increase the physician's knowledge and ability to provide these interventions. ${ }^{[10]}$

Physicians' attitude towards smoking cessation advice has also been reported to affect the involvement of PHC physicians in smoking cessation in the United Kingdom. ${ }^{[8]}$ Similarly, in the Arab world, primary health care physicians reported a positive attitude towards smoking cessation counseling. ${ }^{[11]} \mathrm{Al}$-Ateeq et al. have found attitude to be the critical indicator of physicians' smoking cessation counseling practice and have concluded that assessing physicians' attitudes and identifying and enhancing factors associated with it will improve their smoking cessation counseling practice. ${ }^{[7]}$ There is scant literature in Palestine on smoking cessation counseling, so this study aimed at assessing the compliance of Palestinian PHC physicians and their attitudes towards smoking cessation counseling and their determinants.

\section{METHODS}

\subsection{Study design and sampling}

A cross-sectional research design was used by a self-reported questionnaire targeted at physicians, family doctors, obstet38 rics and gynecologist, and dentists working at PHC centers in Palestine.

A proportionate stratified random sampling method has been applied to determine the sample size for each PHC directorate according to physicians' total number. The sample size was estimated using a confidence level of $95 \%$ and an absolute precision of 0.05 , and an effect size of $50 \%$, resulting in 227 participants. Considering the expected non-response rate among physicians of about $40 \%,{ }^{[12]}$ the sample size calculated was increased to 318. Participants were recruited for the study from April 16, 2019, to the end of September 2019. The response rate was excellent, with 294 questionnaires obtained, reaching $92.5 \%$.

The institutional review board approved the study of AnNajah National University and the Palestinian MoH. Informed consent was obtained from all participants, and their confidentiality and privacy were assured.

\subsection{Measurements and tools}

For data collection, a structured self-administered questionnaire was used. Data were grouped into five sections: sociodemographic, practice compliance, attitude, knowledge, and confidence. Social-demographic data included medical experience (job titles, years of service, workload identified by more than 30 patients per morning shift and having training in smoking cessation) and personal smoking history (smoking status, duration of smoking, cigarette consumption, and if ever had a quit attempt). The practice was measured based on three yes/no statements, "I ask every patient about smoking status, I record every patient status in their medical records, I plan patient follow-up with smoking cessation counseling," and those with a positive response to the three statements were deemed to comply with smoking cessation counseling practice.

The attitude was assessed by eight statements using Likert scale responses. Responses ranged from strongly agree to disagree strongly and neutral. Scores from 5 to 1 were assigned for attitude statements. A "strongly agree" answer was given a score of " 5 " while "agree" was given a score of "4," "neutral" a score of " 3 ," "disagree" "2" and "strongly disagree" response was assigned a score of " 1 ." The overall score for the attitude was reached by adding scores ranging from 9 to 45. The "overall attitude percentage ranking" was then determined by multiplying the total attitude ranking for each participant by 100 and dividing by 40 . A positive attitude was defined as any score equal to and above 65 , while any score below 65 was defined as a negative attitude. ${ }^{[7]}$ For the purpose of analysis, strongly agree and agree responses and strongly disagree and disagree responses were collapsed to "agree" and "disagree" responses, respectively.

ISSN 2377-7338 E-ISSN 2377-7346 
Knowledge and confidence were assessed using ten and six statements, respectively. The total knowledge score was obtained by adding the scores (range from 0 to 10). An "overall knowledge percent score" was then calculated by multiplying the total knowledge score for each participant by 100 and dividing by 10 . The total confidence score was obtained by adding the scores for statements ranging from 5 to 30. An "overall confidence percent score" was calculated by multiplying each participant's total confidence score by 100 and dividing by 30 . Good knowledge and confidence were assigned for any score 65 and above.

The questionnaire was built after a thorough review of the literature. ${ }^{[2,7,13-15]}$ Some of its domains have been taken from pre-validated tools that have been adopted with the permission of the corresponding authors. ${ }^{[7,16]}$ A pilot study and pre-testing of the questionnaire were performed using 20 PHC physicians to ensure the tool's validity and reliability. Face and content were evaluated by asking three experts to revise the questionnaire and give their opinion. Cronbach's alpha was computed and found as $91 \%$ for attitude statements, $72 \%$ and $65 \%$ for confidence and knowledge statements, respectively, indicating very good reliability.

\subsection{Data analysis}

Statistical package for social science (SPSS) version 20 was used for data analysis. The data was checked for entry errors (data clearance). Characteristics of the sample were granted through descriptive analysis. Chi-square assessed the relation between background variables, knowledge, and confidence, and attitude with a $p$-value of $\leq .05$ significance level. Finally, binary logistic regression was carried out to determine the factors associated with a positive attitude considering the possible confounders.

\section{RESUlts}

\subsection{Characteristics of the sample}

A total of 294 PHC physicians participated in this study. More than half $(53 \%)$ were between 31 and 45 years of age, nearly three-quarters of them were male $(75.5 \%)$, most of them (85.7\%) were married, and 156 (53\%) were ever smokers. In terms of their specialization, most of them were general practitioners $(76.5 \%)$, with more than 30 patients per day (about $66 \%$ of the total sample). Almost half of them (47.6\%) had between 6 and 15 years of practical experience, while $36 \%$ had more than 16 years of experience. As shown in Table 1 , only $15 \%(n=40)$ undergo smoking cessation counseling training.

Compliance with smoking cessation counseling practice was low; only $39(13.3 \%)$ reported compliance. Males were more compliant than female doctors (14\% of males compared to $11 \%$ of females). The GPs and those with higher years of experience were more compliant. One-fourth of those who had training reported compliance, compared to $10.7 \%$ of those who had no training, and $15.9 \%$ of those who had never smoked reported compliance, compared to $10.9 \%$ of those who had never smoked, as shown in Table 1 . None of these differences reached a significant level, as the only significant associations were the relationship between compliance with practice and work overload, training, quit, and confidence.

\subsection{Physicians' attitude toward smoking cessation coun- seling practice}

The participant physicians' attitude level was deemed high as the total mean score was $75.1 \pm 9.6$. A positive attitude, ascribed to any score $\geq 65$, was observed in $87.7 \%(n=258)$ of physicians.

About attitude statements results, most physicians (94\%) agreed that giving brief smoking cessation advice as part of their duties, $83.6 \%$ agreed that the presence of guidelines and special clinics for smoking cessation encourage them to provide advice. More than $80 \%$ of physicians generally disagreed that giving such advice was time-consuming or not effective (84.4\%, 80\%, respectively). Nearly $90 \%$ of them agree that brief smoking cessation advice helps quit, and $81.4 \%$ agreed that brief smoking cessation advice needs special training, as seen in Table 2.

Using the Chi-square test, univariate analysis showed a significant association between positive attitude and Job title, experience, and knowledge $p$-value $\leq .05$, as seen in Table 3.

Multivariate logistic regression showed that job title, experience, and knowledge are associated with a positive attitude towards smoking cessation counseling. General practitioners are 2.5 times more likely to have a positive attitude towards smoking cessation counseling than dentists $(p$-value $=.04$. Furthermore, having long years of experience is associated with a positive attitude ( $p$-value $=.008)$. Also, having a good knowledge is significantly associated with a positive attitude towards smoking cessation counseling practice $(p$-value $=$ $.001)$, as seen in Table 4. 
Table 1. Frequencies and percentages of background variables in relation to practice compliancec

\begin{tabular}{|c|c|c|c|c|}
\hline \multirow[t]{2}{*}{ Items } & \multirow[t]{2}{*}{ Variables } & \multicolumn{2}{|c|}{$\begin{array}{l}\text { Compliance to smoking cessation } \\
\text { counseling practice }\end{array}$} & \multirow[t]{2}{*}{ Total $(n=294)$} \\
\hline & & Yes $(\mathbf{n}=39)$ & No $(n=255)$ & \\
\hline \multirow{2}{*}{ Gender } & Male & $31(14 \%)$ & $191(86 \%)$ & $222(75.5 \%)$ \\
\hline & Female & $8(11.1 \%)$ & $64(88.9 \%)$ & $72(24.5 \%)$ \\
\hline \multirow{3}{*}{ Age groups } & $\leq 30$ years & $9(14.5 \%)$ & $53(85.5 \%)$ & $62(21.2 \%)$ \\
\hline & 31-45years & $16(10.3 \%)$ & $139(89.7 \%)$ & $155(53.1 \%)$ \\
\hline & $45-60$ years & $14(18.7 \%)$ & $61(81.3 \%)$ & $75(25.7 \%)$ \\
\hline \multirow{2}{*}{ Marital status } & Married & $32(12.7 \%)$ & $220(87.3 \%)$ & $252(85.7 \%)$ \\
\hline & Unmarried & $7(16.7 \%)$ & $35(83.3 \%)$ & $42(14.3 \%)$ \\
\hline \multirow{3}{*}{ Job title } & GP & $34(15.1 \%)$ & $191(84.9 \%)$ & $225(76.5 \%)$ \\
\hline & Specialist & $3(10.3 \%)$ & $26(89.7 \%)$ & $29(9.8 \%)$ \\
\hline & Dentist & $2(5 \%)$ & $38(95 \%)$ & $40(13.6 \%)$ \\
\hline \multirow{3}{*}{ Experience } & $\leq 5$ years & $6(11.8 \%)$ & $45(88.2 \%)$ & $51(17.3 \%)$ \\
\hline & $6-15$ years & $7(12.1 \%)$ & $123(87.9 \%)$ & $140(47.6 \%)$ \\
\hline & $\geq 16$ years & $16(15.5 \%)$ & $87(84.5 \%)$ & $103(35 \%)$ \\
\hline \multirow{2}{*}{ Work overload ${ }^{*}$} & Yes & $27(13.9 \%)$ & $167(86.1 \%)$ & $194(66 \%)$ \\
\hline & No & $11(11.5 \%)$ & $85(88.5 \%)$ & $96(33 \%)$ \\
\hline \multirow{2}{*}{ Training $(\mathrm{n}=255)^{*}$} & Yes & $10(25 \%)$ & $30(75 \%)$ & $40(15.7 \%)$ \\
\hline & No & $23(10.7 \%)$ & $192(89.2 \%)$ & $215(84.3 \%)$ \\
\hline \multirow{2}{*}{ Smoking status } & Ever & $17(10.9 \%)$ & $139(89.1 \%)$ & $156(53 \%)$ \\
\hline & Never & $22(15.9 \%)$ & $116(84.1 \%)$ & $138(47 \%)$ \\
\hline \multirow{2}{*}{ Quit attempt $(\mathrm{n}=141)^{*}$} & Yes & $15(16.1 \%)$ & $78(83.9 \%)$ & $93(66 \%)$ \\
\hline & No & $2(4.2 \%)$ & $46(95.8 \%)$ & $48(34 \%)$ \\
\hline \multirow{2}{*}{ Knowledge } & Good & $14(17.3 \%)$ & $67(82.7 \%)$ & $81(27.6 \%)$ \\
\hline & Poor & $25(11.7 \%)$ & $188(88.3 \%)$ & $213(72.4 \%)$ \\
\hline \multirow{2}{*}{ Confidence $^{*}$} & Good & $31(19.1 \%)$ & $131(80.9 \%)$ & $162(55 \%)$ \\
\hline & Poor & $124(94 \%)$ & $8(6 \%)$ & $132(45 \%)$ \\
\hline
\end{tabular}

Note. ${ }^{*}$ Significant association by chi-square

Table 2. Frequency and percentage distribution of physicians' response attitude and statements

\begin{tabular}{|c|c|c|c|}
\hline Attitude statements & $\begin{array}{l}\text { Agree } \\
\text { Frequency (\%) }\end{array}$ & $\begin{array}{l}\text { Don’t know } \\
\text { Frequency }(\%)\end{array}$ & $\begin{array}{l}\text { Disagree } \\
\text { Frequency (\%) }\end{array}$ \\
\hline Giving brief smoking cessation advice is part of my duties $(+)$ & $276(93.9)$ & $3(1)$ & $15(5.1)$ \\
\hline $\begin{array}{l}\text { The presence of guidelines and special clinics for smoking } \\
\text { cessation will encourage me to provide advice }(+)\end{array}$ & $246(83.7)$ & $17(5.8)$ & $31(10.5)$ \\
\hline $\begin{array}{l}\text { Smoking cessation advice should be given regardless of present } \\
\text { complain }(+)\end{array}$ & $241(82)$ & $3(1)$ & $50(17)$ \\
\hline Brief smoking cessation advice needs special training (-) & $240(81.4)$ & $5(1.7)$ & $49(16.7)$ \\
\hline $\begin{array}{l}\text { If the physician is a smoker, he should not give smoking cessation } \\
\text { advice to his patients (-) }\end{array}$ & $71(24.1)$ & $3(1)$ & $220(74.8)$ \\
\hline Brief smoking cessation advice is helpful in quitting $(+)$ & $264(89.8)$ & $15(5.1)$ & $15(5.1)$ \\
\hline Brief smoking cessation advice is time-consuming (-) & $30(10.2)$ & $16(5.4)$ & $248(84.4)$ \\
\hline Brief smoking cessation advice is not effective (-) & $41(13.9)$ & $18(6.1)$ & $235(80)$ \\
\hline
\end{tabular}


Table 3. Determinants of positive attitude among participants

\begin{tabular}{|c|c|c|c|c|c|}
\hline \multirow{2}{*}{ Item } & \multirow{2}{*}{ Variable } & \multicolumn{2}{|c|}{ Attitude } & \multirow{2}{*}{$\chi^{2}$ value } & \multirow{2}{*}{$p$-value } \\
\hline & & Positive Frequency (\%) & Negative Frequency (\%) & & \\
\hline \multirow{2}{*}{ Gender } & Male & $194(87.4)$ & $28(12.6)$ & \multirow{2}{*}{0.114} & \multirow{2}{*}{.7} \\
\hline & Female & 64 (88.9) & $8(11.1)$ & & \\
\hline \multirow{3}{*}{ Age groups } & $\leq 30$ years & $55(88.7)$ & $7(11.3)$ & \multirow{3}{*}{3.7} & \multirow{3}{*}{.15} \\
\hline & 31-45years & $131(84.5)$ & $24(15.5)$ & & \\
\hline & $45-60$ years & $70(93.3)$ & $5(6.7)$ & & \\
\hline \multirow{2}{*}{ Marital status } & Ever Married & $223(88.5)$ & $29(11.5)$ & \multirow{2}{*}{0.89} & \multirow{2}{*}{.34} \\
\hline & Single & $35(83.3)$ & $7(16.7)$ & & \\
\hline \multirow{3}{*}{ Job title } & GP & $201(89.3)$ & $24(10.7)$ & \multirow{3}{*}{7.3} & \multirow{3}{*}{.025} \\
\hline & Specialist & $27(93.1)$ & $2(6.9)$ & & \\
\hline & Dentist & $30(75)$ & $10(25)$ & & \\
\hline \multirow{3}{*}{ Experience } & $\leq 5$ years & $46(90.2)$ & $5(9.8)$ & \multirow{3}{*}{6.25} & \multirow{3}{*}{.04} \\
\hline & $6-15$ years & $116(82.9)$ & $24(17.1)$ & & \\
\hline & $\geq 16$ years & $96(93.2)$ & $7(6.8)$ & & \\
\hline \multirow{2}{*}{ Workload } & Overload & $169(87.1)$ & 25 (12.9) & \multirow{2}{*}{0.26} & \multirow{2}{*}{.87} \\
\hline & Acceptable & $85(88.5)$ & $11(11.5)$ & & \\
\hline \multirow{2}{*}{ Training $(\mathrm{n}=255)$} & Yes & $34(85)$ & $6(15)$ & \multirow{2}{*}{0.26} & \multirow{2}{*}{.6} \\
\hline & No & 189 (87.9) & $26(12.1)$ & & \\
\hline \multirow{2}{*}{ Smoking status } & Ever & $136(87.2)$ & $20(12.8)$ & \multirow{2}{*}{0.64} & \multirow{2}{*}{.42} \\
\hline & Never & $122(88.4)$ & $16(11.6)$ & & \\
\hline \multirow{2}{*}{ Knowledge } & Good & $77(95.1)$ & $4(4.9)$ & \multirow{2}{*}{5.5} & \multirow{2}{*}{.019} \\
\hline & Poor & $182(85)$ & $32(15)$ & & \\
\hline \multirow{2}{*}{ Confidence } & Good & $142(87.8)$ & $20(12.3)$ & \multirow{2}{*}{0.007} & 03 \\
\hline & Poor & $117(88)$ & $16(12)$ & & \\
\hline
\end{tabular}

Table 4. Multivariable analysis of factors associated with a positive attitude

\begin{tabular}{|c|c|c|c|c|c|}
\hline Domain & $\beta$ & SE & Adjusted OR & $p$-value & $95 \%$ CI \\
\hline \multicolumn{6}{|l|}{ Job title } \\
\hline GP & 0.96 & 0.46 & $2.6^{*}$ & .04 & $1.1-6.5$ \\
\hline $\begin{array}{l}\text { Specialist } \\
\text { Dentist }^{\dagger}\end{array}$ & 1.53 & 0.84 & $4.6^{*}$ & .072 & $0.9-24$ \\
\hline \multicolumn{6}{|l|}{ Experience } \\
\hline$\leq 5$ years & -0.8 & 0.66 & 0.45 & .2 & $0.12-1.6$ \\
\hline $\begin{array}{l}6-15 \text { years } \\
\geq 16 \text { years }\end{array}$ & -1.3 & 0.5 & $0.27^{*}$ & .008 & $0.1-0.7$ \\
\hline Knowledge & 0.037 & 0.01 & $1.03^{*}$ & .0001 & $1.02-1.05$ \\
\hline
\end{tabular}

\section{Discussion}

Factors that influence the implementation of evidence-based guidance remain poorly understood. ${ }^{[17]}$ Training, attitudes, and beliefs of health care providers and organizational and environmental influences have been reported to affect guidelines. ${ }^{[18]}$ Literature regarding the association between attitude and practice showed that a positive attitude is not always associated with best practice. ${ }^{[11,19,20]}$ This is in line with our Published by Sciedu Press findings, as the high level of attitude towards smoking cessation counseling among PHC physicians contradicted their low level of practice.

Attitude has recently been widely studied by behavioralists in various fields. As part of the theoretical study, attitudes to help design interventions to change healthcare professionals' behavior have become increasingly relevant in the health care field. ${ }^{[21]}$ The theory of reasoned action (TRA) and planned behavior (TPB) is based on the fundamental premise that an individual's intentions can predict actions. Thus, the intention is an immediate antecedent of behavior and is a feature of behavioral attitude, subjective norm, and perceived behavioral control. ${ }^{[22]}$

In the light of a high level of positive attitude towards smoking cessation counseling in Palestine and a low level of compliance with relevant practices, subjective norms and perceived behavioral control are expected to play a role in forming physician practice. Studies in Palestine have shown a high prevalence of smoking in the population with a rapid rise in teenagers and a high impact of peers and families 
on smoking habits. ${ }^{[23,24]}$ It concluded that the Palestinian culture's subjective norms are conducive to smoking rather than smoking cessation. That is the case even in the medical community, as more than half of PHC physicians are ever smokers, $42 \%$ are current smokers in this study. On the other hand, physicians' perception of their ability to provide smoking cessation counseling, assessed as confidence, is seen as positive and related to best practice compliance, emphasizing the need to explore other obstacles that could influence physician compliance.

Given the importance of attitudes in predicting and explaining human behavior, a critical question arises: where do they come from? The "tripartite" method suggested by Zanna $\&$ Rempel provides that attitudes are developed based on acquired knowledge (cognition), emotional stimuli (affect), and past behaviors and outcomes. ${ }^{[25]}$ Applying this approach, we can assume that PHC physicians in Palestine have a clear understanding of smoking cessation practice. Concerning emotional effects about the high level of attitude among study participants, almost all PHC physicians in Palestine feel that brief smoking cessation advice is part of their duties. Most do not think that being a smoker physician prohibits them from giving smoking cessation advice, as shown in Table 2.

Moreover, past behavioral outcomes have affected behaviors, which was apparent in the insignificant relationship between the prior quit attempt and the attitude to smoking cessation counseling, which may seem contradictory. But with further analysis; tow third of those with quit attempts are still current smokers. Quit attempt was significantly associated with greater compliance with smoking cessation counseling among our physicians. Most of them did not quit and had a poor understanding of smoking cessation therapy, making it a priority to increase the expertise of PHC physicians in smoking cessation counseling.

Variables external to planned behavior theory, like personality traits and demographic variables, influence behavior by affecting the underlying beliefs and influencing intention. ${ }^{[26]}$ Experienced physicians and those with better knowledge regarding smoking cessation counseling reported a better attitude. Findings in this setting were comparable to regional studies in Saudi Arabia. Physicians with more ample working experience in PHC centers and physicians with higher education levels reported a more positive attitude reflected on their practice in smoking cessation counseling. ${ }^{[7,11]}$
Additionally, policy and conductive environment can play a significant role in adherence to guidelines. The Palestinian legislation (no-smoking laws), passed in 2005, banned tobacco advertising/promotion, smoking in public places, and selling cigarettes to minors. However, there seems to be no existing system to enforce the legislation and link them to strategic planning in the health sector. Furthermore, PHC physicians' who get no training about smoking cessation counseling and facing overcrowded clinics with a lack of adequate staff are deprived of a conducive environment to support this practice.

This research is one of the few that examined the factors influencing the attitude of PHC physicians to smoking cessation practices. Since Palestine is a small country, the study has implemented a random sampling method targeting all PHC doctors with a high response rate. On the other hand, some limitations should be considered. The study utilized a cross-sectional design with its limits, and social desirability bias might be of concern as a self-reported attitude and smoking status by physicians could probably be underestimated due to the community's perceived image of doctors, which sees in them healthy role models.

\section{Conclusion}

A high level of attitude towards smoking cessation counseling has been observed among PHC physicians, significantly affected by better knowledge and experience. However, this high level of attitude was not reflected in their practice, as only 39 (13\%) of PHC physicians reported compliance. While physicians have a good understanding of the need for smoking cessation counseling and have a positive intention towards practicing it, other factors such as subjective norms, policy enforcement, and conducive environment influence smoking cessation counseling compliance. Building a supportive environment, improving physicians' capabilities, reflecting on their self-efficacy may increase physicians' confidence and improve their practice. The implication for future research in this field is strongly recommended as to explore barriers towards counseling and to assess the effects of interventions aimed to improve PHC physicians' knowledge in smoking cessation on their practice.

\section{CONFlicts of InTERest Disclosure}

The authors declare no conflicts of interest. 


\section{REFERENCES}

[1] WHO. Tobacco Free Initiative (TFI). Available from: https : //ww w. who. int/tobacco/mpower/offer/en/. Published 2019. Accessed December 17, 2019.

[2] World Health Organization. WHO I Toolkit for Delivering the 5A's and 5R's Brief Tobacco Interventions to TB Patients in Primary Care; 2014. Available from: https://www . who. int/tobacco/public ations/smoking_cessation/9789241506946/en/

[3] Siu AL, for the U.S. Preventive Services Task Force. Behavioral and Pharmacotherapy Interventions for Tobacco Smoking Cessation in Adults, Including Pregnant Women: U.S. Preventive Services Task Force Recommendation Statement. Ann Intern Med. 2015; 163(8): 622-634. PMid:26389730. https : //doi .org/10.7326/M15-202 3

[4] CDC. Best Practices for Comprehensive Tobacco Control Programs. Atlanta: U.S. Department of Health and Human Services, Centers for Disease Control and Prevention, National Center for Chronic Disease Prevention and Health Promotion, Office on Smoking and Health. 2014; 1-24.

[5] Bartsch AL, Harter M, Niedrich J, et al. A Systematic Literature Review of Self-Reported Smoking Cessation Counseling by Primary Care Physicians. PLoS One. 2016; 11(12): e0168482. PMid:28002498. https://doi.org/10.1371/journal.pone.0 168482

[6] Lina M, Mazza R, Borreani C, et al. Hospital doctors' smoking behavior and attitude towards smoking cessation interventions for patients: a survey in an Italian Comprehensive Cancer Centre. Tomori. 2016; 102(3): 244-251. PMid:27079902. https ://doi.org/10.5301/ tj. 5000501

[7] Al-Ateeq M, Alrashoud A, Khair M, et al. Smoking cessation advice: The self-reported attitudes and practice of primary health care physicians in a military community, central Saudi Arabia. Patient Prefer Adherence. 2016; 10: 651-658. PMid:27175065. https://doi .org/10.2147/PPA.S103010

[8] Stead M, Angus K, Holme I, et al. Factors influencing European GPs \& engagement in smoking cessation: a multi-country literature review. Br J Gen Pract. 2009; 59(566): 682 LP-690. PMid:19674514. https://doi.org/10.3399/bjgp09X454007

[9] Naeem M, Irfan M, Mawani M, et al. Tobacco Cessation Treatment: Knowledge, Attitude and Practices of Physician in Karachi, Pakistan: A Cross Sectional Study. J Heal Med Nurs. 2016; 27(June): 90-97.

[10] Nobile CGA, Bianco A, Biafore AD, et al. Are primary care physicians prepared to assist patients for smoking cessation? Results of a national Italian cross-sectional web survey. Prev Med (Baltim). 2014; 66: 107-112. PMid:24945695. https ://doi .org/10.1016/j .yp med. 2014.06.009

[11] Al-Turkstani AHM, Alkail BA, Hegazy AA, et al. Knowledge, attitude, and practice among primary health-care physicians toward smoking cessation in Makkah, Saudi Arabia. Int J Med Sci Public Heal. 2016; 5(04): 714-724. https://doi.org/10.5455/ijms ph. 2016.13112015224

[12] Abdulaziz K, Brehaut J, Taljaard M, et al. National survey of physicians to determine the effect of unconditional incentives on response rates of physician postal surveys. BMJ Open. 2015; 5(2). PMid:25694460. https://doi.org/10.1136/bmjopen-2 014-007166

[13] Matouq A, Khader Y, Khader A, et al. Knowledge, attitude, and behaviors of health professionals towards smoking cessation in primary healthcare settings. Transl Behav Med. 2018; 8(6): 938-943. PMid:29444289. https : //doi .org/10.1093/tbm/ibx045
[14] Abdullah AS, Stillman FA, Yang L, et al. Tobacco Use and Smoking Cessation Practices among Physicians in Developing Countries: A Literature Review (1987-2010). Int J Env Res Public Heal. 2013; 11(1): 429-455. PMid:24380976. https://doi.org/10.3390/ij erph110100429

[15] Klink K, Lin S, Elkin Z, et al. Smoking Cessation Knowledge, Attitudes, and Practice Among Community Health Providers in China. Fam Med. 2011; 43(3): 198-200.

[16] Abdullah ASM, Rahman ASMM, Suen CW, et al. Investigation of Hong Kong doctors' current knowledge, beliefs, attitudes, confidence and practices: implications for the treatment of tobacco dependency. J Chin Med Assoc. 2006; 69(10): 461-471. https: //doi .org/10.1016/S1726-4901 (09)70310-7

[17] Grimshaw J, Eccles M, Tetroe J. Implementing clinical guidelines: current evidence and future implications. J Contin Educ Health Prof 2004; 24 Suppl 1: S31-7. PMid:15712775. https ://doi .org/10 $.1002 / \operatorname{chp} .1340240506$

[18] Ploeg J, Davies B, Edwards N, et al. Factors Influencing Best-Practice Guideline Implementation: Lessons Learned from Administrators, Nursing Staff, and Project Leaders. Worldviews Evidence-Based Nurs. 2007; 4(4): 210-219. PMid:18076464. https://doi.org/ $10.1111 / \mathrm{j} .1741-6787.2007 .00106 . \mathrm{x}$

[19] Labi AK, Obeng-Nkrumah N, Bjerrum S, et al. Physicians' knowledge, attitudes, and perceptions concerning antibiotic resistance: a survey in a Ghanaian tertiary care hospital. BMC Health Serv Res. 2018; 18(1): 126. PMid:29458432. https://doi.org/10.1186/ s12913-018-2899-y

[20] Mathatha ED, Manamela JM, Musekiwa A, et al. Exploring the knowledge, attitudes and practices (KAP) of health care professionals on viral hepatitis notification in Gauteng, South Africa, 2015. Arch Public Heal. 2018; 76(1): 75. PMid:30555693. https : //doi.org/10.1186/s13690-018-0319-8

[21] Godin G, Bélanger-Gravel A, Eccles M, et al. Healthcare professionals' intentions and behaviours: A systematic review of studies based on social cognitive theories. Implement Sci. 2008; 3(1): 36 PMid:18631386. https://doi.org/10.1186/1748-5908-3-3

[22] Ajzen I. The theory of planned behavior. In: Handbook of Theories of Social Psychology, Vol. 1. Thousand Oaks, CA: Sage Publications Ltd; 2012. 438-459 p. https : //doi .org/10.4135/9781446249 $215 . \mathrm{n} 22$

[23] Nazzal ZM, Al-Halaweh A, Musmar S. Prevalence of water-pipe smoking and associated factors among university students in Palestine: a cross sectional study. Palest Med Pharm J. 2020; 5(2): $107-$ 601.

[24] Nazzal Z, Al-Halaweh MA, Musmar S. Social Norms and Perception of Waterpipe Smoking among Palestinian University Students. Vol 5.; 2020. Available from: https ://journals . najah.edu/media /journals/full_texts/3_a3KxcIa.pdf, Accessed October 28, 2020 .

[25] Zanna MP, Rempel JK. Attitudes: A new look at an old concept. In: The Social Psychology of Knowledge. Paris, France: Editions de la Maison des Sciences de l'Homme; 1988. 315-334 p.

[26] Dehghanpour Farashah A. The effects of demographic, cognitive and institutional factors on development of entrepreneurial intention: Toward a socio-cognitive model of entrepreneurial career. J Int Entrep. 2015; 13(4): 452-476. https ://doi.org/10.1007/s10843-015 $-0144-\mathrm{x}$ 